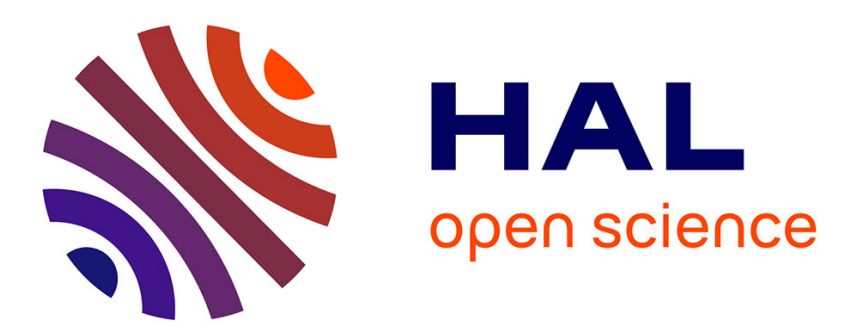

\title{
Viscosity and radial distribution function in PbxSe (1-x) melts for stoechiometric and peritectic compositions
}

\author{
G. Chaussemy, A. Laugier
}

\section{To cite this version:}

G. Chaussemy, A. Laugier. Viscosity and radial distribution function in PbxSe (1-x) melts for stoechiometric and peritectic compositions. Journal de Physique Lettres, 1979, 40 (19), pp.529-532. 10.1051/jphyslet:019790040019052900 . jpa-00231680

\section{HAL Id: jpa-00231680 https://hal.science/jpa-00231680}

Submitted on 1 Jan 1979

HAL is a multi-disciplinary open access archive for the deposit and dissemination of scientific research documents, whether they are published or not. The documents may come from teaching and research institutions in France or abroad, or from public or private research centers.
L'archive ouverte pluridisciplinaire HAL, est destinée au dépôt et à la diffusion de documents scientifiques de niveau recherche, publiés ou non, émanant des établissements d'enseignement et de recherche français ou étrangers, des laboratoires publics ou privés. 


\title{
Viscosity and radial distribution function in $\mathrm{Pb}_{x} \mathrm{Se}_{(1-x)}$ melts for stoechiometric and peritectic compositions
}

\author{
G. Chaussemy \\ Laboratoire de Physique Electronique, Université Claude-Bernard, \\ 43, bd du-11-Novembre-1918, 69621 Villeurbanne Cedex, France
}

and A. Laugier

Laboratoire de Physique de la Matière $(*)$, Institut National des Sciences Appliquées de Lyon, 20, avenue Albert-Einstein, 69621 Villeurbanne Cedex, France

(Reçu le 21 mai 1979, révisé le 24 juillet 1979, accepté le 17 août 1979)

\begin{abstract}
Résumé. - On a étudié le liquide $\mathrm{Pb}_{x} \mathrm{Se}_{(1-x)}$ entre 680 et $1160^{\circ} \mathrm{C}$ pour $x=0,24$. On montre que le modèle de sphère dure et le formalisme du volume libre peuvent décrire correctement la viscosité cinématique. On considère des unités structurales constituées d'atomes de plomb entourés par des atomes de sélénium. L'énergie d'interaction entre unités vaut $0,36 \mathrm{eV}$ pour le liquide stœchiométrique et $0,29 \mathrm{eV}$ près du péritectique. Ces résultats confirment l'hypothèse de liquide associé déjà suggérée par les données thermodynamiques.
\end{abstract}

\begin{abstract}
Liquid alloy $\mathrm{Pb}_{x} \mathrm{Se}_{(1-x)}$ was studied near to the peritectic composition $x=0.24$ between 680 and $1160{ }^{\circ} \mathrm{C}$. The hard sphere model is extended to this binary system. Structural units formed by lead atoms surrounded by $\mathrm{Se}$ atoms are considered. Kinematic viscosity data are compared with the values computed in the free volume formalism. The interaction energy $\varepsilon^{*}$ between structural units was deduced $: \varepsilon^{*}=0.36 \mathrm{eV}$ for pure PbSe. It is smaller near the peritectic composition : $0.29 \mathrm{eV}$. These data confirm the liquid associated model already suggested for this liquid by thermodynamic data.
\end{abstract}

1. Introduction. - The chemical bonds for the $\mathrm{NaCl}$ structure of lead selenide are covalent-ionic. The short range order of the solid is conserved in the liquid state by the structural units, at least near the melting point $[1,2]$. The rapid fall of electrical conductivity during melting indicates that $\mathrm{PbSe}$ has a molecular structure in the liquid state rather than a chain-structure [1]. Viscosity is very sensitive to chemical bonding and short range order, the latter can well be studied by means of neutron diffraction. It is the case for liquid $\mathrm{Pb}$ [3] and $\mathrm{Se}$ [4]. Viscosities of lead and selenium are known. The interatomic binding energy in liquid lead is about $0.06 \mathrm{eV}$ [5], and, as suggested by viscosity data [6], could be much greater for selenium. Thermodynamic data indicate that $\mathrm{Pb}_{x} \mathrm{Se}_{(1-x)}$ melts are strongly associated liquids [2, 7], therefore the viscosity behaviour is essentially governed by $\mathrm{Pb}-\mathrm{Se}$ and $\mathrm{Se}-\mathrm{Se}$ bonds. We have remeasured the viscosity of $\mathrm{PbSe}$ in order to

(*) Equipe de recherche associée au C.N.R.S. precise the results previously obtained by Glazov [1]. The $x=0.24$ composition has been choosen in order to have a large temperature range between the liquidus line and our experimental upper limit (1 $\left.150^{\circ} \mathrm{C}\right)$.

A simple hard sphere model provides a satisfactory basis for the interpretation of viscosity data of dense fluids, such as liquid metallic alloys [8] and molten salts [9]. For this latter, the hard core size $\sigma$ deduced from viscosity measurements is related to the position of the first or second peak of the radial distribution function $[10,11]$, indicating the existence of a relation between $\sigma$ and the mean spacings in quasi ordered melts.

In metallic liquids, $\sigma$ can also be regarded as the average distance of closest approach for repulsive collisions [12]. In both cases mentioned above, $\sigma$ is assumed to be temperature dependent. In this work, a hard sphere model is extended to $\mathrm{Pb}_{0.24} \mathrm{Se}_{0.76}$ liquid and to molten $\mathrm{PbSe}$.

2. Experimental method. - 2.1 NEUTRON DIFFRACTION. - The results were obtained using $1.138 \AA$ 
wavelength neutrons at the EL 3 reactor (Saclay). The compounds were synthetized and placed in a quartz ampoule sealed under $10^{-3} \mathrm{mmHg}$ Argon residual pressure. Compounds were heated in a H.F. furnace with P.I.D. temperature regulation. An angular range of $116^{\circ}$ was examined with steps of $15^{\prime}$ and a counting duration of $6 \mathrm{~min}$ was used for each angle. Data were treated according to reference [13]. Corrections were made for absorption in order to consider only neutrons diffracted by the sample. A second correction was necessary because simultaneous elastic and inelastic scattering occurs but a correction for multiple scattering was not applicable (less than $0.1 \%$ ).

2.2 Vicosity. - The kinematic viscosity was determined with an oscillating cup viscometer [1, 14]. The pendulum was placed under reduced pressure in a resistance, non-inductive oven in which the temperature was controlled by two thermocouples and a P.I.D. temperature regulation. The ampoules, internally coated with a pyrocarbon layer, were filled with the required weights of pure lead and selenium $(99.999 \%)$; air was evacuated and replaced with argon under reduced pressure $(100 \mathrm{mmHg})$ before sealing. The ampoules were placed in the viscometer and heated for complete homogeneization at temperatures above the melting point of $\mathrm{PbSe}$. Fabrication of ampoules must be carefully controlled to ensure a perfect cylindrical form. After the experiment the ampoules were cut open and the internal diameter measured. An error of about $10 \%$ was estimated for the absolute viscosity value, however; measuring the temperature dependence of the viscosity, the relative precision was estimated to be $4 \%$.

3. Results. - 3.1 RADIAL DISTRIBUTION FUNCTION. - The radial distribution function $g(r)$ is presented in figure 1 for $\mathrm{Pb}_{0.30} \mathrm{Se}_{0.70}$ at $850{ }^{\circ} \mathrm{C}$. Four maximum values are observed :

- The first maximum is at $r: 2.10 \AA$. This value is different from the position of the first peak of $g(r)$ in liquid selenium recently obtained by Tourand [15] : $2.335 \AA$ at $700^{\circ} \mathrm{C}$ and $2.330 \AA$ at $900^{\circ} \mathrm{C}$. It is also different for lead : $3.3 \AA$ at $850^{\circ} \mathrm{C}$ [3].

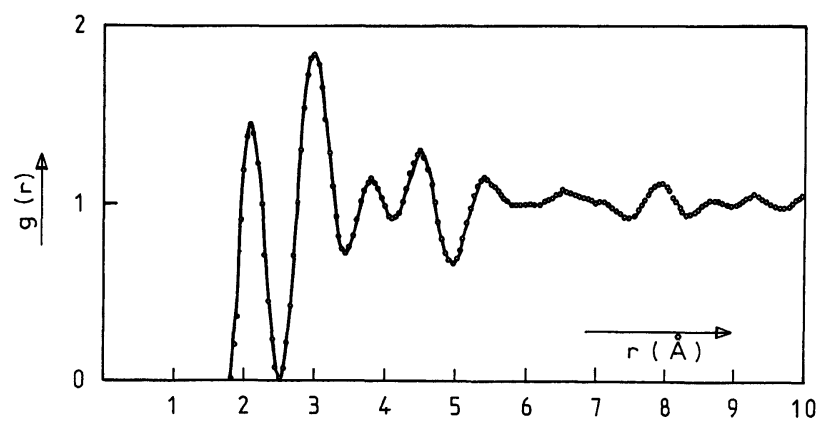

Fig. 1. - Total radial distribution function $g(r)$ for $\mathrm{Pb}_{0.30} \mathrm{Se}_{0.76}$ at $850^{\circ} \mathrm{C}$
- The second maximum position ( $r=3 \AA)$ corresponds to the magnitude of the distance between lead and selenium atoms in solid PbSe (3.06 $\AA)$.

- The positions of the 3rd and 4th peaks (3.8 and $4.5 \AA)$ are comparable with distances observed in liquid selenium (3.75 and $4.51 \AA$ at $460^{\circ} \mathrm{C}$ ).

This correlation is surprising because of the difference in the position of the first peak and the difference in structure, as discussed later.

3.2 Viscosity. - For pure lead, $\mathrm{PbSe}$ and $\mathrm{Pb}_{0.24} \mathrm{Se}_{0.76}$, the viscosity results versus, reciprocal temperature $(I / T)$ are plotted in figure 2 . The $\mathrm{Pb}$ and $\mathrm{PbSe}$ viscosity data are in close agreement with the Arrhenius law $\left(v=v_{0} \exp \frac{W}{k T}\right)$ with the apparent activation energies $W$ respectively equal to 0.07 and $0.4 \mathrm{eV}$. For $\mathrm{Pb}_{0.24} \mathrm{Se}_{0.76}$ melts, a small curvature is observed and the apparent activation energy lies between 0.2 and $0.3 \mathrm{eV}$. For dynamic viscosity $\eta$, such as $\eta=v d$, where $d$ is the density, the respective activation energies are $0.087,0.43$ and $0.25-0.32 \mathrm{eV}$.

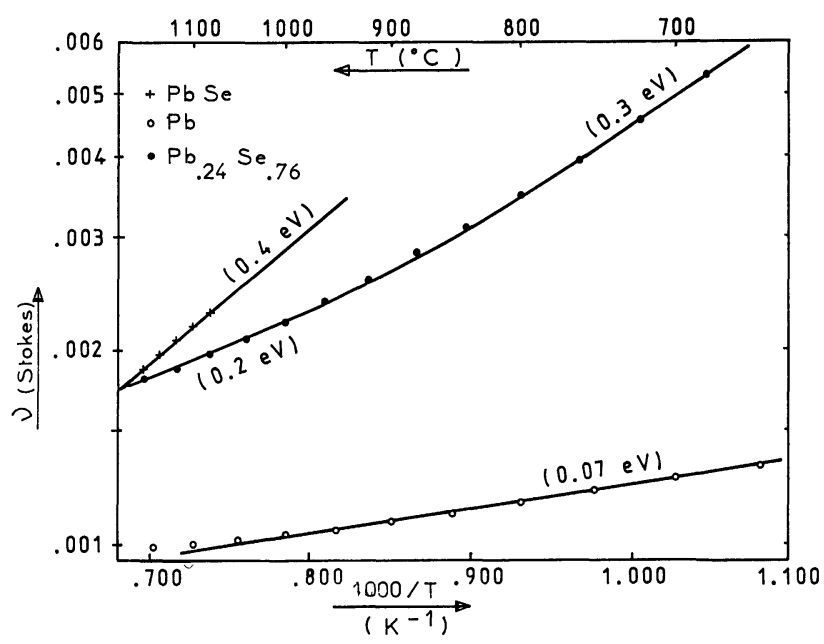

Fig. 2. - Experimental values of kinematic viscosity $v$ for pure lead, lead selenide and $\mathrm{Pb}_{0.24} \mathrm{Se}_{0.76}$. The apparent activation energy $W$ of the Arrhenius law $v=v_{0} \exp \left(\frac{W}{k T}\right)$ is indicated for each liquid.

For $\mathrm{PbSe}$ our results are 10 to $15 \%$ higher than those obtained by Glazov [1]. The temperature range investigated is small. Consequently the precision for $W$ is poor and a comparison of activation energies is not significative. The values of density $d$ used for $\mathrm{PbSe}$ and $\mathrm{Se}$ are given in reference [1]. For $\mathrm{Pb}_{x} \mathrm{Se}_{(1-x)}$ melts, an approximate value of $d$ can be calculated assuming that these liquids are ideal solutions of $\mathrm{PbSe}$ and Se.

4. Analysis and discussion. - Glazov suggests a molecular structure for $\mathrm{PbSe}$. Thermodynamic data $[2,7]$ support the concept of strong association in the liquid alloys $\mathrm{Pb}_{x} \mathrm{Se}_{(1-x)}$. The existence of a 
demixing zone in the Se rich part of the phase diagram agrees also with this hypothesis. Small amounts of impurities can perturb strongly the structure of Se. We have measured the viscosity in Se doped with $\mathrm{Pb}(x<0.1 \%)$ but no significant differences were observed. The effect of thallium is more important and was recently observed [16]. This impurity reduces the chain length. In the Tl-Se system a demixing zone is also seen. So, two different structures of the liquid can be considered in the $\mathrm{PbSe}-\mathrm{Se}$ range : first, near Se, the structure is Se-like with chains. Between the stoechiometric and peritectic composition, the structure is of molecular type. There, a hard sphere model can be used with the following assumption : a quasi-ordered structural unit exists, the size of which is comparable to the position of a peak of $g(r)$. The first, second, and so on peaks are considered, if these units are respectively extended to the first, second and so on neighbouring atoms.

The kinematic viscosity can be written [3] :

$$
\begin{gathered}
v=\frac{6.59 \times 10^{-5} T^{1 / 2} M^{-1 / 6}}{\left\{1+\left(\frac{\varepsilon^{*}}{k T}\right)+\frac{1}{2}\left(\frac{\varepsilon^{*}}{k T}\right)^{2}\right\}}\left(\frac{\zeta}{d}\right)^{1 / 3} \times \\
\times \exp \left\{\frac{\zeta}{\zeta_{0}-\zeta}+\frac{\varepsilon^{*}}{k T}\right\} .
\end{gathered}
$$

$M$ is the molar mass. $\zeta$ is the packing fraction and $\zeta_{0}=0.74$ the value for hard packing. The free volume formalism is considered [17, 18] and an activation energy $\varepsilon^{*}$ is included $[19,20]$ to account for the interacting force between structural units. The well known Stokes-Einstein relationship between selfdiffusion and viscosity coefficients is assumed to be valid. As the Stokes-Einstein constant is not exactly known, this model is only an approach. It is interesting to note that if the binding energy is small $\left(\varepsilon^{*} \rightarrow 0\right)$, eq. (1) is formally the same as the equation used for liquid metal alloys by Rialland [21].

$\zeta$ is related to the density $d$, the molar mass $M$ and the hard core size $\sigma$ by the following equation, where $N$ is the Avogadro's number :

$$
\zeta=\frac{N \pi}{6} \frac{d}{M} \sigma^{3} .
$$

For $\mathrm{Pb}_{x} \mathrm{Se}_{(1-x)}$ compounds, the association corresponds to the following chemical equation :

$$
x \mathrm{~Pb}+(1-x) \mathrm{Se} \rightarrow x \mathrm{PbSe}+(1-2 x) \mathrm{Se} .
$$

Using eq. (1) the experimental values of $v$ can be fitted with $\varepsilon^{*}$ and $\zeta$ acting as adjustable parameters. The $\sigma$ values are deduced with the aid of eq. (2).

\begin{tabular}{|c|c|c|c|c|c|c|}
\hline \multicolumn{2}{|l|}{$T\left({ }^{\circ} \mathrm{C}\right)$} & $v(\mathrm{cS})$ & $\zeta$ & $\sigma(\AA)$ & $\sigma_{\text {calc }}(\AA)$ & $\frac{\sigma-\sigma_{\text {calc }}}{\sigma} \times 10^{3}$ \\
\hline \multicolumn{2}{|l|}{-} & - & - & 一 & - & - \\
\hline $\mathrm{PbSe}$ & 1080 & 0.229 & 0.345 & 2.808 & 2.808 & +0.1 \\
\hline \multirow[t]{4}{*}{$\left(\varepsilon^{*}=0.36 \mathrm{eV}\right)$} & 1100 & 0.217 & 0.338 & 2.791 & 2.792 & -0.3 \\
\hline & 1120 & 0.207 & 0.332 & 2.775 & 2.775 & +0.1 \\
\hline & 1140 & 0.197 & 0.326 & 2.760 & 2.759 & +0.5 \\
\hline & 1160 & 0.187 & 0.319 & 2.741 & 2.742 & -0.4 \\
\hline \multirow[t]{2}{*}{$\mathrm{Pb}_{0.24} \mathrm{Se}_{0.76}$} & 680 & 0.534 & 0.434 & 3.078 & 3.071 & +2.4 \\
\hline & 720 & 0.454 & 0.422 & 3.058 & 3.054 & +1.2 \\
\hline \multirow[t]{11}{*}{$\left(\varepsilon^{*}=0.29 \mathrm{eV}\right)$} & 760 & 0.395 & 0.411 & 3.039 & 3.038 & +0.4 \\
\hline & 800 & 0.346 & 0.399 & 3.019 & 3.021 & -0.9 \\
\hline & 840 & 0.310 & 0.389 & 3.001 & 3.005 & -1.4 \\
\hline & 880 & 0.282 & 0.380 & 2.986 & 2.990 & -1.3 \\
\hline & 920 & 0.256 & 0.370 & 2.967 & 2.974 & -2.3 \\
\hline & 960 & 0.238 & 0.362 & 2.956 & 2.959 & -1.1 \\
\hline & 1000 & 0.220 & 0.353 & 2.939 & 2.944 & -1.7 \\
\hline & 1040 & 0.208 & 0.347 & 2.931 & 2.930 & +0.3 \\
\hline & 1080 & 0.197 & 0.340 & 2.921 & 2.915 & +1.9 \\
\hline & 1120 & 0.186 & 0.333 & 2.909 & 2.901 & +2.6 \\
\hline & 1160 & 0.181 & 0.330 & 2.910 & 2.887 & +7.8 \\
\hline
\end{tabular}

Table I. - v is the experimental value of kinematic viscosity, which can be calculated from eq. (1) and the packing fraction $\zeta$ of column 3. The hard core diameter $\sigma$ is deduced using eq. (2).

$$
\begin{aligned}
\sigma_{\text {calc }} & =5.07\left\{1-0.45\left(\frac{T}{1350}\right)^{1 / 2}\right\} \text { for } \mathrm{PbSe} \\
& =3.88\left\{1-0.21\left(\frac{T}{950}\right)^{1 / 2}\right\} \text { for } \mathrm{Pb}_{0.24} \mathrm{Se}_{0.76}
\end{aligned}
$$


The values for $\varepsilon^{*}$ and $\zeta$ are arbitrary. $\varepsilon^{*}$ can be considered independent of temperature $T$. As indicated above, $\sigma$ can be correlated to the position of a peak in $g(r)$. The best fit is obtained with the second peak. With $\sigma=3 \AA$ at $850^{\circ} \mathrm{C}, \varepsilon^{*}$ is found to be $0.36 \mathrm{eV}$ for $\mathrm{PbSe}$ and 0.29 for the peritectic. The $\zeta$ and $\sigma$ values are given in table I. This table shows that $\sigma$ varies slowly with temperature.

Assuming that the collisions are elastic and that the interaction potential between structural units is parabolic around the equilibrium position $\sigma_{0}$, Protopapas et al. [12] have obtained the following relation :

$$
\sigma=\sigma_{0}\left\{1-B\left(\frac{T}{T m}\right)^{1 / 2}\right\} .
$$

This relation also seems to be verified in the present case.

A least square method gives the following values for $\sigma_{0}$ and $B: 5.07 \AA$ and 0.45 for PbSe, $3.88 \AA$ and 0.21 respectively for the peritectic. The calculated value $\sigma_{\text {cal }}$ is plotted table I. Below $1120^{\circ} \mathrm{C}\left(\sigma-\sigma_{\text {cal }}\right) / \sigma$ does not exceed $0.26 \%$.

5. Conclusion. - The $\varepsilon^{*}$ values agree with the assumption that $\mathrm{F}_{\mathrm{Pb}-\mathrm{se}}$ bonding forces are stronger than the $\mathrm{F}_{\mathrm{Se}-\mathrm{Se}}$ ones. In liquid $\mathrm{Pb}-\mathrm{Se}$, short range order is the same as that in the solid state with $\mathrm{NaCl}$ structure : the structural units consisting of one lead atom surrounded by selenium atoms. For viscous flow, the $\mathrm{Pb}-\mathrm{Se}$ bonds must be broken. The equilibrium distance between lead atoms is then similar to the half lattice parameter in the $\mathrm{NaCl}$ cubic structure of the solid; this assumption is consistent with the large value of $\sigma_{0}$ observed in lead selenide.

For $\mathrm{Pb}_{0.24} \mathrm{Se}_{0.76}$, the structural units are modified and each lead atom can exhibit four covalent bonds with selenium atoms forming a pseudotetrahedron $\mathrm{PbSe}_{4}$. This is consistent with the observation on $g(r)$ : the peak corresponding to pure lead at $r=3.3 \AA$ at $850^{\circ} \mathrm{C}[17]$ is absent.

These conclusions cannot be definitive because the study of the radial distribution functions in the system $\mathrm{Pb}-\mathrm{Se}$ is not yet complete. A thorough study of the structure of $\mathrm{Pb}-\mathrm{Se}$ liquid alloys by neutron diffraction will be published in an other work [22].

Acknowledgments. - This work was sponsored by the C.N.R.S. (A.T.P. Matériaux). The authors acknowledge G. Tourand (Saclay) and M. Schneider (C.N.R.S. Bellevue) for many fructuous discussions and the neutron experiment.

\section{References}

[1] Glazov, V. M., Chizhevskaya, S. N. and Glagoleva, N. N., Liquid Semiconductors (Plenum Press, New York) 1969.

[2] Schneider, M., Thèse, Paris.

[3] North, D. M., Enderby, J. E. and Egelstaff, P. A., J. Phys. C (Proc. Phys. Soc.) Ser. 2, 1 (1968) 1075.

[4] Tourand, G., J. Physique 34 (1973) 937.

[5] Chaussemy, G., J. Physique Lett. (to be published).

[6] Rialland, J. F. and Perron, J. C., Proceedings of the 6th Int. Conf. on Amorph and Liq. Semiconductors. B. A. Kolomiets Ed. (Leningrad) 1976.

[7] Maekawa, T., Yokokawa, T. and Niwa, K., Proceedings of the Second International Conference on the properties of liquid metals. Sakue Tatenchi Taylor and Francis LTD Ed. (London) 1973.

[8] Protopapas, P. and Parlee, N. A. D., Chem. Phys. 11 (1975) 201.

[9] Van Loef, J. J., Z. Naturforsch. 31a (1976) 967.

[10] DupuY, J., Private Communication.

[11] Van Loef, J. J., Da Silva, M. J. and Tricht, J. B., Chem. Phys. Lett. 28 (1974) 508.
[12] Protopapas, P., Andersen, H. C. and Parlee, N. A. D., J. Chem. Phys. 59 (1973) 15.

[13] Tourand, G. and Breuil, M., J. Physique 32 (1971) 813.

[14] Wittemberg, L. J., Techniques of Metal Research, vol. IV (2), R. A. Rapp Ed. (Interscience, New York) 1970.

[15] Tourand, G., Private communication.

[16] Deprez, J., Rialland, J. F. and Perron, J. C., J. Physique Lett. 39 (1978) 142.

[17] Cohen, M. H. and Turnbull, D., J. Chem. Phys. 31 (1959) 1164.

[18] Turnbull, D. and Cohen, M. H., J. Chem. Phys. 34 (1961) 120.

[19] Macedo, P. B. and Litovitz, T. A., J. Chem. Phys. 42 (1965) 245.

[20] Chung, H. S., J. Chem. Phys. 44 (1966) 1362.

[21] Rialland, J. F., Thesis, Orsay, 1977.

[22] SCHNEIDER, M. and Tourand, G. (to be published). 